\title{
La obligatoriedad del precedente judicial frente a las autoridades administrativas colombianas*
}

\author{
The obligation of the judicial procedent before \\ the Colombian administrative authorities
}

\section{RESUMEN}

Con el presente artículo en profundidad, se pretende analizar la fuerza vinculante del precedente judicial para las autoridades administrativas colombianas, en la adopción y ejecución de sus decisiones y actuaciones. Con metodología de análisis hermenéutico de lo jurídico se examinarán sus aspectos sustanciales, tales como el fundamento de dicho deber jurídico y la aplicación o inaplicación del principio de autonomía o independencia de las mencionadas autoridades, para apartarse del precedente judicial; así como su margen de libertad interpretativa, al momento de aplicar una norma a un caso en particular. Igualmente, se analizará si el desconocimiento del precedente judicial en situaciones análogas o similares, por parte de las autoridades en mención, puede acarrear responsabilidad administrativa, disciplinaria o incluso penal del funcionario público.

\section{PALABRAS CLAVE}

Precedente judicial, Responsabilidad del funcionario público, Obligatoriedad del precedente.

\begin{abstract}
Going in-depth in this article, we pretend to analyze the binding force of the judicial precedent for the administrative Colombian authorities, in these adaptation and execution of their decisions and actions. With hermeneutical methodology and legal analysis we will examine, the substantial aspects like the fundament of legal duty and this application and non-application of its principal of authority or independence of the mentioned authorities, to step aside from the judicial precedent: as well as its margin of interpretative freedom, at the moment of norm applying in a particular case. Likewise we will analyze if the ignorance of the judicial precedent is similar or analogous situations on behalf of the mentioned authorities, can cause administrative responsibilities, disciplinary or even criminal of a public official.
\end{abstract}

\section{KEYWORDS}

Judicial precedent, Responsibility of a public official, Mandatory precedent.

\section{CARLOS MANUEL ECHEVERRI CUELLO}

Abogado, Universidad Sergio Arboleda, Especialización en Derecho Público Económico, Universidad Sergio Arboleda. Magíster en Derecho, Universidad Sergio Arboleda. Director Ejecutivo Seccional de Administración Judicial de Valledupar. echecue@yahoo.com

* Este artículo en profundidad es un resumen de la tesis presentada para optar el título de Magíster en Derecho de la Universidad Sergio Arboleda, la cual fue aprobada con calificación meritoria. 


\section{INTRODUCCIÓN}

El tema cuyo análisis se pretender realizar, comprende la obligatoriedad de la jurisprudencia de las Altas Cortes frente al accionar de las autoridades administrativas colombianas. Asunto que ha venido siendo tratado por la Corte Constitucional, respecto de sus decisiones, reiterando que su vinculatoriedad de la ratio decidendi, constituye una norma cuya aplicación se impone a todos los casos que se subsuman dentro de la hipótesis prevista por la regla judicial, la cual debe ser acatada por las autoridades administrativas, pues ellas están obligadas a aplicar el derecho vigente y las reglas judiciales lo son (Sentencia T-569/01).

A lo anterior se suman los deberes a cargo de las autoridades, establecidos en los artículos 10 y 102 de la Ley 1437 de 2011, en virtud de los cuales, respectivamente, aquellas están obligadas a dar aplicación uniforme a las normas y a la jurisprudencia, tanto del Consejo de Estado como de la Corte Constitucional, al igual que extender los efectos de las sentencias de unificación de las corporaciones mencionadas, en las que se hayan reconocido derechos.

El punto de partida del problema, es la necesidad de establecer el fundamento del deber jurídico que estructura la obligatoriedad para que los servidores públicos se vean compelidos a acoger los precedentes judiciales frente a los casos particulares que son sometidos a su conocimiento. En este orden de ideas, es del caso precisar, que las autoridades ad- ministrativas se encuentran limitadas en su actuar por lo que dispone la ley; es decir, que esta es una actividad reglada, carente de toda discrecionalidad.

En principio, podemos afirmar que su actuar está encaminado a cumplir y a hacer cumplir la ley. Desde la Constitución Política misma se establece un marco de competencias reglado para el actuar de quienes fungen como servidores públicos, quienes están sujetos a la ley, entendida esta en sentido material, es decir, al conjunto de normas que conforman el ordenamiento jurídico y dado que las decisiones judiciales forman parte de este, también están en la obligación de cumplirlas.

Pero el problema se puede enmarcar de una parte desde el factor temporal, es decir, el relativo a desde cuándo se debe aplicar el precedente y el factor cualitativo, referente a cuáles son los criterios que deben reunir las decisiones judiciales para que la administración deba entrar a resolver las situaciones particulares fundándose en el precedente jurisprudencial.

Así mismo, es necesario establecer cuál es el alcance del concepto decisiones judiciales, dado que es entendido como los fallos dictados por jueces o tribunales para resolver un conflicto de carácter particular y concreto, pero también, se puede inferir que el precedente judicial surge cuando se adoptan decisiones reiteradas en un mismo sentido. Los resultados de estas reflexiones judiciales, se asimilan como jurisprudencia, la cual posee un carácter vinculante frente a terceros. 
Es así que la Corte Constitucional ha venido estructurando los elementos que se deben tener como vinculantes, referido específicamente en los procesos contenciosos y los fallos de tutela a la parte motiva del fallo, esto es la denominada ratio decidendi, a través de la cual se sientan los criterios formales vinculantes, que el juzgador considera deben ser empleados en casos similares posteriores.

Pero surge la pregunta en cuanto a la facultad que tiene la administración para apartarse de la aplicación del precedente judicial, para cuyo efecto se debe revisar el desarrollo legal y jurisprudencial de esta materia, pero que de antemano en líneas gruesas debemos decir que es inexistente, dadas las características del servicio descritas con anterioridad, enmarcadas dentro de un ámbito eminentemente reglado.

Adicionalmente, el tema obliga a determinar el margen de libertad interpretativa que tienen los servidores para llegar a adoptar una decisión particular y concreta, teniendo en cuenta decisiones en sentido similar adoptadas por las autoridades judiciales. Es decir, que al establecer la actividad de la administración como reglada de forma inmediata limita la facultad interpretativa, puesto que el nivel de discrecionalidad prácticamente queda proscrito. Por otra parte, una vez se logre dilucidar los temas antes planteados se debe entrar a precisar los diferentes tipos de responsabilidad que necesariamente acompañan o determinan el servicio público. De ahí, que la pregunta problema que guió la actividad reflexiva de este trabajo se formule como: ¿Están obligadas las autoridades administrativas a observar los precedentes judiciales, al adoptar las decisiones de su competencia?

La obligatoriedad del precedente judicial para las autoridades administrativas, es un tema que ya ha sido abordado por nuestra jurisprudencia constitucional, tal como fue tratado en las Sentencias T-566/1998 y T-569/01, entre otras. No obstante, el tema recobra vigencia con la promulgación de Ley 1437 de 2011, "Por la cual se expide el Código de Procedimiento Administrativo y de lo Contencioso Administrativo", y los pronunciamientos recientes de la Corte Constitucional sobre los artículos 10 y 102 de la citada norma, realizados a través de las Sentencias C-634/11 y C-816/11, reiterando lo establecido y decidido en la Sentencia C-539/11; en las que se arriba a la conclusión de que las autoridades administrativas deberán tener en cuenta el precedente judicial, tanto del Consejo de Estado como de la Corte Constitucional, al adoptar las decisiones de su competencia y extender los efectos de las sentencias de unificación jurisprudencial de dichas Cortes, en las que se hayan reconocido derechos, a quienes lo soliciten y acrediten los mismos supuestos fácticos y jurídicos.

La Corte Constitucional, en reiterados fallos, ha decantado su doctrina, en torno a la obligación de las autoridades públicas de observar las decisiones judiciales previamente adoptadas, en la solución de casos análogos. Así, se destacan las Sentencias SU-047/99, T-1625/00, C-836/01, Sentencia SU-1300/01 у $\mathrm{T}-057 / 06$. 
En Sentencia T-566/98, la Corte Constitucional analizó el carácter vinculante de la doctrina constitucional en tutela para las autoridades administrativas, quienes no cuentan con la autonomía funcional de los jueces para apartarse de las decisiones judiciales previas. Igualmente, en Sentencia T-569/01, la mencionada Corporación hizo precisiones sobre la obligatoriedad de su jurisprudencia, frente a las autoridades administrativas, quienes están obligadas a aplicar el derecho vigente (y las reglas judiciales lo son), y únicamente están autorizadas a apartarse de las normas, frente a disposiciones claras y abiertamente inconstitucionales (C.P. art. 4). También, mediante la Sentencia T-116/04, el Alto Tribunal señaló que la Administración debe sujetarse a los parámetros definidos por la Corte Constitucional. De manera reciente, en las Sentencias C-634/11 y C-816/11, en las que se reitera la doctrina sentada en la Sentencia C-539/11, la Corte determinó que:

\footnotetext{
"Todas las autoridades públicas, de carácter administrativo o judicial, de cualquier orden, nacional, regional o local, se encuentran sometidas a la Constitución y a la ley, y que como parte de esa sujeción, las autoridades administrativas se encuentran obligadas a acatar el precedente judicial dictado por las Altas Cortes de la jurisdicción ordinaria, contencioso administrativa y constitucional".
}

Por su parte, doctrinantes colombianos también han abordado el asunto, analizándolo desde la perspectiva del Derecho Compa- rado y su tratamiento en el sistema jurídico nacional. Es así como el análisis de la función judicial ha cobrado relevancia en el ámbito de la ciencia jurídica y de la investigación del Derecho Comparado, gracias al prominente trabajo del jurista Diego Eduardo López Medina (2007).

El precedente judicial y su fuerza vinculante son entendidos desde la obra de este reconocido autor, como algo producto de la funcionalidad del cargo del juez, puesto que son los jueces quienes de primera mano se ven abocados a la interpretación del texto jurídico para precisar lo que dice o lo que no dice. Su obra, ofrece en detalle, cómo la Corte Constitucional ha entendido y ha usado la doctrina del precedente desde la instauración de un derecho producto en sus orígenes de copias de otros órdenes de carácter greco-romano. Al respecto nos dice Rubén Sánchez Gil (2009, p. 401):

"El juez tiene un papel muy importante como creador jurídico, al pronunciar el derecho que dirime una determinada controversia, y más aún si los criterios que utiliza al desempeñar su función tienen valor vinculante para instancias de inferior jerarquía, por lo cual debe tenerse muy clara la naturaleza de estos criterios y las reglas que en virtud de ella deben seguirse para su utilización práctica".

Es de anotar que López Medina (2007) entiende lo jurídico como un campo de tensiones entre las decisiones de los jueces y 
el ordenamiento político coyuntural, lo que hace que exista una pugna entre dos grandes apuestas teóricas, que el autor denomina como la teoría tradicionalista y la teoría nueva. La primera le da muchísima fuerza al rol del legislador como primera y única fuente y la segunda le da un papel protagónico a la figura del juez como, intérprete y creador dinámico de lo jurídico. Otra de las obras de López (2002), en la que también aborda el tema de la fuerza vinculante del precedente judicial, es Interpretación constitucional con la cual, entre otras cosas, busca dar herramientas concretas de interpretación constitucional e investigación jurisprudencial para analizar, en espacios de tiempo y en coyunturas específicas, la forma cómo evolucionan las decisiones de los jueces.

Sobre los problemas que enfrenta la teoría del precedente en el contexto colombiano, la jurista colombiana María Buitrago Guzmán (2011), en su trabajo de tesis de Maestría, realiza un excelente mapa cognitivo de los problemas fundamentales del precedente judicial. Ella señala seis grandes problemas: 1. El precedente debe enfrentar el problema de la cultura legalista en la formación de los abogados en Colombia, esta cultura niega que el derecho es esencialmente un producto humano y que por lo tanto carga las emociones, los sentimientos y las pasiones de un determinado contexto político y social. 2. La existencia de múltiples ideologías y valores en el marco normativo de la Constitución de 1991, hace bastante dispendioso encontrar una línea que agrupe todos estos "techos ideológicos". 3. La abultada y gigante pro- ducción normativa en Colombia, producto de la reformitis, la "convulsión legislativa" y el síndrome normativo (Botero Bernal, 2003) hace que agrupar en líneas jurisprudenciales los precedentes sea una tarea titánica. 4. El desconocimiento del precedente por los organismos de cierre fiscal. 5. El cambio permanente de magistrados y de las Cortes, afecta de una forma directa la jurisprudencia. 6. La ausencia de consensos en los organismos de cierre que implica toma de decisiones basadas en la mayoría.

De igual forma, es destacable el trabajo de Carlos Bernal Pulido (2008), donde se aborda el problema de si las sentencias judiciales tienen el carácter de precedente en el sistema jurídico colombiano, y si es así, cuál es el fundamento, cuáles las características y cuál el alcance de este carácter. En el marco de los diferentes análisis de la fuerza vinculante del precedente judicial es pertinente señalar el trabajo de posesión como miembro correspondiente de la Academia Colombiana de Jurisprudencia de Eduardo Pilonieta Pinilla (2007).

No menos importante es el trabajo de Julio Alberto Tarazona Navas (2007), en el que trata temas relacionados con la vinculatoriedad de las decisiones judiciales, tales como la "Supremacía o Imperio del Precedente Constitucional" y la "Teoría sobre la Obligatoriedad del Precedente Constitucional", entre otros. Asimismo, se destaca el trabajo realizado por Gómez y Robles (2011) en el que se propone un análisis crítico sobre la certeza de la transformación y crisis de las fuentes 
del Derecho en el contexto nacional. Al respecto las mencionadas autoras precisan que:

"La jurisprudencia constitucional proferida por la Corte Constitucional en Colombia, se ha desarrollado en un momento álgido de la historia nacional $y$, aunque este no ha sido un aspecto sustantivo del presente discurso, sí lo ha sido enunciar la lucha por el derecho de la colectividad, como legitimante del actuar del operador jurídico. En otras palabras, el juez asume un papel de garante del querer social y la jurisprudencia constitucional, le brinda las herramientas necesarias para lograr este altísimo cometido" (Gómez y Robles, 2011, p. 466).

A pesar de esta amplia y variada gama de análisis, el precedente judicial y su accionar se ha enmarcado en el campo del debate constitucional, donde sin lugar a dudas, ha sido estudiado con suficiente amplitud, siendo valioso el hecho de que aún no exista ningún tipo de acuerdo definitivo sobre las posturas a asumir. En el caso de la administración, de los operadores jurídicos y de los funcionarios públicos, es notoria la ausencia de trabajos encaminados al análisis del precedente, dado que esta figura es bastante novedosa y solo aparece actualmente con la reforma al Código de Procedimiento Administrativo.

Este trabajo se encamina en esa dirección. Por ende, se pretende profundizar en la fuerza vinculante del precedente judicial en las actividades y funciones propias de los servidores públicos. Para alcanzar esta finalidad se emplearon metodologías propias de la hermenéutica jurídica bajo la égida de la investigación descriptiva, que según Hernández, Fernández y Baptista (2010, p. 80): “... busca especificar propiedades, características y rasgos importantes de cualquier fenómeno que se analice".

Para ello, se inicia con el ejercicio de caracterizar globalmente el precedente judicial en la perspectiva del Derecho Comparado de forma aproximativa y general, se continúa con un acercamiento que pretende precisar el precedente judicial en Colombia y se finaliza el trabajo con el aparte que persigue caracterizar la fuerza vinculante del precedente judicial en el marco normativo de la Ley 1437 de 2011 para el caso de los funcionarios públicos.

\section{El precedente jurisprudencial en el Dere- cho Comparado}

\subsection{La tradición anglosajona}

Iniciamos nuestro recorrido por una de las tradiciones más antiguas en cuanto a fuerza institucional vinculante: el ordenamiento jurídico inglés. El precedente jurisprudencial constituye una de las columnas cardinales del Derecho inglés. En dicho sistema jurídico, la actividad inductiva del juez es fundamental, tanto en la interpretación de las leyes expedidas por el Parlamento, como en la creación del derecho. Esta doctrina del precedente judicial, denominada el "Derecho de los Casos" (case law), ha permitido que, 
a partir de las decisiones de casos anteriormente resueltos, los jueces ingleses creen reglas, principios y criterios jurídicos, vinculantes en la solución de casos análogos.

En el common law, el basamento de la fuerza vinculante del precedente judicial, que es fuente del ordenamiento jurídico, lo constituye el principio stare decisis, es decir, estarse a lo resuelto en los casos anteriores. Esto obliga a los tribunales a respetar las sentencias proferidas con anterioridad por ellos mismos o por los tribunales jerárquicamente superiores, al decidir sobre casos análogos por sus hechos. De allí que, el sustento de los recursos de apelación radique en la incorrecta aplicación del precedente judicial (appeals by way of case stated). En relación con la obligatoriedad de los fallos con valor de precedente judicial y su carácter de fuente del Derecho inglés, Marta Mirneau (2004, pp. 23 y 24) expresa lo siguiente:

"Esta regla implica que cuando un juez conoce de un asunto, o sea, de un caso antes de emitir un fallo deber considerar las decisiones de otros jueces, en casos anteriores, que se relacionen con los mismos hechos, dentro de una particular rama del Derecho. Esas decisiones, en lo que toca a los puntos de derecho invocado, constituirán los precedentes judiciales. El hecho de recurrir a ellos, tiene por objeto reafirmar los principios jurídicos aplicables al asunto de que se trate, logrando además, consistencia en los fallos. Se considera que los precedentes de los tribunales superiores son obligatorios y vinculatorios para ellos mismos, así como para los tribunales jerárquicamente inferiores, y que son los jueces de estos últimos los que al invocar el fallo anterior, le confieren la calidad de precedente judicial".

En el ordenamiento jurídico estadounidense, el precedente obligatorio, fundado en la regla del stare decisis, constituye el soporte histórico de las sentencias de la Corte Suprema, las cuales deben ser acatadas, tanto por la misma Corporación, como por los diferentes tribunales de los Estados de la Unión. En palabras de María Ángeles Ahumada Ruiz (2003, p. 356):

"La dinámica que impone el stare decisis es fácil de describir. En virtud de este principio los jueces han de decidir los casos del presente atendiendo a cómo se decidieron casos iguales o semejantes en el pasado. En sentido horizontal, el stare decisis fuerza la vinculación del juez a sus decisiones anteriores. En sentido vertical, a las de los tribunales superiores que ejercen sobre ellos jurisdicción en apelación. En principio, los jueces no están obligados por precedentes establecidos por tribunales de su mismo rango, ni por los de tribunales de apelación sin jurisdicción sobre ellos. Por ello se suele distinguir entre precedentes vinculantes y precedentes persuasivos dependiendo de la relación que liga a unos tribunales con otros (un prece- 
dente obligatorio para unos tribunales será persuasivo para otros). Los únicos precedentes con fuerza obligatoria para todos los jueces son los que proceden del Tribunal Supremo (en el caso de los Estados Unidos, en materias de derecho federal)".

Hechas las anteriores precisiones, es necesario anotar que si bien el sistema jurídico norteamericano tuvo sus orígenes en un Derecho eminentemente jurisprudencial importado desde Inglaterra, Estados Unidos adoptó un sistema de Common law con características propias. En efecto, en lo referente al stare decisis, el Common law estadounidense presenta una cierta autonomía, frente al Common law inglés, en tanto que este otorga al precedente una verdadera firmeza, haciendo excepcional para el juez la posibilidad de apartarse de él. Mientras que en Estados Unidos la regla de la obligatoriedad del precedente judicial, no tiene el mismo rigor en su aplicación, lo que facilita que un tribunal norteamericano pueda desconocer sus propios precedentes. Esta situación encuentra explicación, según Nuria González Martín (2011, p. 392), en el hecho de que:

“(...) los Estados de la Unión son soberanos en relación con su régimen interno y por ello cuentan con su propia organización judicial. Es así, entonces, que en el país existen tribunales federales y tribunales locales y, como las cortes superiores de los Estados pueden establecer precedentes, esta circunstancia provocaría diferencias irreductibles entre los derechos de los Estados, si la regla del stare decisis no se aplicara de una manera flexible".

En el mismo sentido, al comparar el sistema jurídico inglés y el sistema jurídico estadounidense, García Martínez y Torres Zárate (2008, p. 98) concluyen que:

“(...) aunque el derecho americano descienda del inglés, existen marcadas diferencias entre ambos sistemas, que obedecen principalmente a razones históricas y políticas. Entre las primeras hay que señalar que en la formación del derecho de Estados Unidos permearon influencias diversas, tales como las costumbres de los pueblos indios originarios de ese país, así como el derecho de otros países de Europa como: Holanda, Francia y España, que también fueron parte de su colonización. Sin dejar de considerar que quien sentó las bases del derecho norteamericano fue en definitiva Inglaterra. Por otro lado, consideramos que las diferencias más importantes en este sistema surgen por la estructura política que adoptó después de su independencia, toda vez que esta fue constituida como República Federal, lo que implicó 50 sistemas jurídicos locales perviviendo al lado de un federal".

\subsection{El enfoque latinoamericano}

En el sistema jurídico argentino, tradicionalmente, el precedente jurisprudencial no tuvo el carácter vinculante, tal como ocurre 
en el sistema del common law con la doctrina del staredecisis. Por eso, los tribunales no estaban obligados a respetar y acatar las reglas preexistentes, sentadas en sus propios fallos o en las decisiones anteriores, adoptadas por los tribunales de jerarquía superior. Esta situación produjo una jurisprudencia diversa carente de unidad. No obstante, en el siglo XX, se introdujeron transformaciones en el ordenamiento jurídico argentino, a través de leyes de índole procesal que permitieron a los tribunales sentar doctrina obligatoria para sí mismos y para los tribunales jerárquicamente inferiores. Incluso, a nivel provincial, sin mediar norma habilitante, reglas locales han atribuido obligatoriedad a la doctrina sentada por la Corte Suprema y por los tribunales superiores.

Específicamente, en el caso "Cerámica San Lorenzo", fallado el 4 de julio de 1985, la Corte Suprema de Justicia de la Nación, impuso a los tribunales el deber de acatar sus fallos, al considerar que:

“(...) no obstante que la Corte Suprema solo decide en los procesos concretos que le son sometidos, y su faIlo no resulta obligatorio para casos análogos, los jueces inferiores tienen el deber de conformar sus decisiones a aquellas emana la consecuencia de que carecen de fundamento las sentencias de los tribunales inferiores que se apartan de los precedentes de la Corte sin aportar nuevos argumentos que justifiquen modificar la posición sentada por el tribunal, en su carácter de intérprete supremo de la Constitución Nacional y de las leyes dictadas en su consecuencia" (Corte Suprema de Justicia de la Nación. Fallo 1985/07/04. Cerámica San Lorenzo, S. A. Buenos Aires, julio 4 de 1985).

Al respecto, Néstor Pedro Sangûés (2006, pp. 27 y 28 ) manifiesta que:

"Puede hablarse entonces de una jurisprudencia vinculante $u$ obligatoria de la Corte, pero condicionada: el tribunal inferior está habilitado para apartarse de ella, siempre que dé fundamentos que sean: a) valederos; y b) diferentes a los ya examinados por la Corte. De hecho, esta regla importa una interpretación mutativa por adición al texto constitucional, que suma a las competencias de la Corte Suprema enunciadas inicialmente en la Constitución (...) cuya legitimidad, hoy día, se funda en razones parecidas al stare decisis estadounidense (...): igualdad, previsibilidad y economía. Son estos valores muy prácticos que la sociedad contemporánea cotiza significativamente, y que consolidan al peculiar stare decisis argentino, que como su par norteamericano, aunque no de modo idéntico, recorta las facultades de juzgamiento de los jueces y el mismo control difuso de constitucionalidad, al imponerles límites acerca de cómo deben resolver".

Siguiendo con este recorrido de Derecho Comparado, el precedente vinculante en el ordenamiento jurídico peruano, es una ins- 
titución relativamente nueva, que ha tenido su principal desarrollo en el ámbito constitucional. Efectivamente, la obligatoriedad del precedente constitucional cuenta con respaldo normativo, tal como lo establece el Artículo VII del Título Preliminar del Código Procesal Constitucional, aprobado por la Ley 28237 de 2004, cuyo tenor es el siguiente:

"Las Sentencias del Tribunal Constitucional que adquieren la autoridad de cosa juzgada constituyen precedente vinculante cuando así lo exprese la sentencia, precisando el extremo de su efecto normativo. Cuando el TC resuelva apartándose del precedente, debe expresar los fundamentos de hecho y de derecho que sustentan la sentencia y las razones por las cuales se aparta del precedente... ...el precedente constitucional vinculante es aquella regla jurídica expuesta en un caso particular y concreto que el Tribunal Constitucional decide establecer como regla general; $y$, que, por ende, deviene en parámetro normativo para la resolución de futuros procesos de naturaleza homóloga. El precedente constitucional tiene por su condición de tal, efecto similar al de una ley. Es decir, la regla general externalizada como precedente a partir de un caso concreto se convierte en una regla preceptiva común que alcanza a todos los justiciables y que es oponible frente a los poderes públicos. En puridad, la fijación de un precedente constitucional significa que ante la existencia de una sentencia con unos específicos fundamentos o argumentos y una decisión en un determinado sentido, será obligatorio resolver los futuros casos semejantes según los términos de dicha sentencia" (Sentencia del Tribunal Constitucional del Perú. Exp. 0024-2003-Al/TC. Lima, Municipalidad Distrital de Lurín. 10 días del mes de octubre de 2005).

Con respecto a la aplicación del precedente constitucional en la jurisprudencia peruana, Ricardo Guillermo Vinatea Medina (2010, pp. 4 y 5) ha señalado que:

“(...) que cuando en el ámbito público o privado, el magistrado se encuentre ante una sentencia que está constituida como precedente vinculante, con unos fundamentos o argumentos jurídicos y con un fallo en un sentido determinado, se obliga a resolver los futuros casos semejantes según los términos de esa primera sentencia. Este precedente que esté configurado en algunas sentencias del Tribunal Constitucional vincula tanto a los jueces y magistrados del Poder Judicial, como a los propios magistrados del Tribunal Constitucional en los casos semejantes que en el futuro tengan que resolver, salvo se trate del apartamiento de su línea jurisprudencial. El precedente vinculante se da en el marco de los procesos constitucionales que conoce el Tribunal Constitucional, esto incluye los procesos competenciales, 
que el Tribunal decide en instancia única; y los procesos de amparo, habeas corpus, habeas data y acción de cumplimiento, que el Tribunal decide en última instancia. En los procesos mencionados las sentencias del supremo intérprete de la Constitución que adquieren la autoridad de cosa juzgada constituyen precedente vinculante cuando lo señale la propia sentencia, indicando qué extremo de su decisión tendrá efecto normativo, en su parte resolutiva. La particularidad de las sentencias que formarán al precedente vinculante es que el Tribunal Constitucional debe resolver una controversia definida por concretas circunstancias; ya que estamos hablando de procesos en los que el órgano constitucional debe decidir -afectando solo a las partes en el proceso-, y declarando fundada o infundada la demanda, si una determinada actuación pública o privada ha vulnerado el contenido de un derecho fundamental que se encuentra protegido por la Constitución. Es en este marco particular en el que el Tribunal Constitucional puede dar valor general, con efectos erga omnes a determinados fundamentos de la sentencia que reúnan los requisitos para constituirse como precedentes vinculantes y que el Tribunal exprese su decisión formulándolos como tales".

Después de este breve recorrido, podemos apreciar que el debate en Colombia sigue los mismos derroteros trazados por las realida- des del Derecho Internacional. Veamos de manera general la forma cómo se ha construído el debate sobre el precedente judicial en Colombia.

\section{El precedente jurisprudencial en Colom- bia \\ 2.1. Las tensiones de los dos enfoques en el marco jurídico colombiano}

En el ordenamiento jurídico colombiano, dentro de las fuentes formales del Derecho encontramos la jurisprudencia, distinguida de una parte como las decisiones adoptadas por los jueces, para dirimir los conflictos o diferencias entre dos partes, en cuyo caso se constituyen en normas de carácter particular $y$, de la otra, como las decisiones generales que sobre un objeto similar pueda tomarse como orientadora para exigir de los jueces su aplicación en el mismo sentido, convirtiéndose en normas de carácter general.

En ese sentido, al precedente judicial se le reconoce la misma fuerza vinculante de una norma jurídica, que si bien no es expedida por el Congreso de la República (Rama Legislativa) o por el Ejecutivo, su fuente reiterada o unificada sobre el análisis de una temática, en ausencia de disposiciones o a falta de su claridad, permite a los coasociados contar con un referente de interpretación. Ello desde luego, en la práctica genera estabilidad y limita el ámbito de discrecionalidad del fallador cuando se presenten casos similares, con relación a la decisión que debe adoptar o la necesidad de sustentar su variación, fundado en elementos objetivos. 
En diferentes fuentes encontramos referencia a dos sistemas en los cuales ha evolucionado la figura del precedente judicial, como son propiamente el precedente en el sistema anglosajón o Common law y la forma que adquiere a partir de la jurisprudencia en los países de influencia en el Derecho romano referidos a los países de la Europa Continental.

El sistema anglosajón aplicado en el Reino Unido y sus antiguas colonias, parte de un Derecho consuetudinario de naturaleza oral que propone un esquema mediante el cual las decisiones de los jueces, a falta de un desarrollo legal al ser sistemas de Constituciones no escritas o con desarrollos legales limitados, tienen un carácter obligatorio, a diferencia del surgido de los países con influencia romana en los cuales existe una marcada tendencia a la rigidez legal; es decir, que son las normas escritas las que regulan las relaciones entre los particulares y entre estos y el Estado, en el cual las decisiones de los jueces se limitan a ser interpretativas de las normas y no sus creadoras.

Como se expresó en otro aparte, en el Common law, las decisiones de los tribunales tienen un carácter de precedente, que no pueden ser modificadas a menos que cambien los presupuestos que dieron lugar a ello y los cuales deberán ser sustentados por las mismas instancias o superiores a estas. En este orden de ideas, se puede afirmar que en sentido estricto la jurisprudencia en el sistema romano-germánico no era tenida como verdadera fuente del Derecho, sino como un criterio auxiliar del juez.
Es decir, que la jurisprudencia como fuente de Derecho, en los países que conservan dicho sistema o son influenciados por este, al no tener mayor fuerza vinculante, pasa a ser como en el caso de la doctrina, un elemento de juicio sustitutivo para el juez y las partes. Ello se conservó en el Sistema Jurídico Colombiano hasta el surgimiento de la Constitución de 1991, con el advenimiento del Tribunal Constitucional Ilamado Corte Constitucional, que está llamada a servir de guardiana de la Constitución.

Dicho sea de paso, la creación de un sistema jerarquizado y que cuenta con un tribunal de esta naturaleza, dedicado a defender los principios básicos de la Constitución Política, tiende a desconocer la tradición y desarrollo jurisprudencial, al igual que el derecho natural como fuente de derecho anterior y superior a la Constitución misma, lo cual, es a todas luces, inconveniente para la seguridad jurídica del país.

En presencia de la Constitución de 1886 se observó un relativo desarrollo para lograr que las decisiones de los jueces al ser reiteradas tuviesen una fuerza vinculante como es el caso de lo previsto en el artículo 4 de la Ley 53 de 1887 o por el artículo 10 de la Ley 153 de 1887, subrogado por la Ley 169 de 1896, esta última en el sentido de que tres decisiones uniformes de la Corte Suprema de Justicia como Tribunal de Casación constituyen doctrina probable y que los jueces podían aplicarlas en casos análogos. Sin embargo, obsérvese que la norma establecía una facultad discrecional para el juez al emplear ese criterio auxiliar. 
Esto se contrapone a la figura contemplada en el sistema anglosajón según la cual la ratio decidendi de una sentencia de un tribunal, obliga a este y a sus inferiores funcionales a fallar en el mismo sentido. Se considera que el sistema romano-germánico tiene grandes debilidades en esta materia, puesto que permite que en casos similares, los jueces interpreten de forma diferente los vacíos normativos o la ausencia de normas en un caso particular, máxime entendiendo que es necesario en muchos casos acudir a este "criterio auxiliar" para no denegar justicia.

Por el contrario, la consistencia normativa derivada del análisis realizado por el juez con la inmediatez de las pruebas y contando con los argumentos de las partes, que se traduce en una sentencia, al ser conocida y tomada como precedente permite tener una mayor consistencia y estabilidad jurídica. En nuestro medio, el paso de la decisión potestativa al afianzamiento del precedente judicial como lo contempla el sistema anglosajón, pasa por las decisiones de la Corte Constitucional pero de forma inicial únicamente referida a derechos fundamentales.

Es allí que surge el precedente judicial como un avance en nuestro ordenamiento jurídico en la medida en que los jueces dejan de ser meros intérpretes de la norma jurídica y pasan a llenar efectivamente los vacíos por la falta de desarrollo normativo o ausencia de claridad de los mismos.

La Ley 1437 de 2011, constitutiva del Código de Procedimiento Administrativo y de lo
Contencioso Administrativo, que entró en vigor a mediados del año 2012, hace referencia directa a la "Extensión de la jurisprudencia", en el entendido de que a partir de la entrada en vigencia de dicha norma, las autoridades deberán extender los efectos de una sentencia de unificación jurisprudencial a quienes lo soliciten y acrediten los mismos supuestos fácticos y jurídicos. De igual forma, establece el procedimiento para la extensión de la jurisprudencia del Consejo de Estado a terceros (artículos 102 y 269 Ley 1437 de 2011). También se establece que todo cambio de jurisprudencia sobre el alcance y contenido de la norma deber ser motivado.

Para plantear el análisis del precedente jurisprudencial, debemos hacer mención al lugar que la jurisprudencia tiene en el sistema de fuentes del Derecho, buscando establecer si esta se constituye en fuente formal principal del Derecho o es un mero criterio auxiliar para los jueces y la administración pública. En ese sentido debemos distinguir el sistema de Common law o Derecho común inglés, surgido en la Inglaterra medieval, del sistema de Derecho continental europeo, con profundas raíces romanas, cuya estructura se vio reforzada por el surgimiento de la Revolución Francesa que trajo consigo criterios como la necesidad de que exista tridivisión de poderes públicos, con miras a garantizar un sistema de pesos y contrapesos del poder. Sin embargo, es del caso precisar que la tradición jurídica inglesa se asemeja al modo en que operaban los jurisconsultos o juristas romanos, quienes debido a la gran dispersión de normas debieron simplificar el ordena- 
miento legal, creando de esa forma doctrina judicial que fue utilizada en casos similares posteriores.

Así mismo, la Revolución Francesa trajo consigo la aplicación de conceptos como el relativo a que la función del juez es la de ser la boca de la ley; es decir, que viene a reforzar la noción romano-germánica en cuanto a que la fuente del Derecho por excelencia es la ley, con un corte eminentemente positivista. Es así que en el Common law los tribunales y jueces deben destrabar los conflictos o fallar, teniendo en cuenta las decisiones que con anterioridad han adoptado los tribunales o jueces, lo cual no quiere decir que no puedan apartarse de estas, pero siempre han de partir del precedente judicial y tenerlo como referente directo.

Por su parte, en el Derecho continental europeo, los jueces deben adoptar sus decisiones con fundamento en la ley exclusivamente, dejando de lado cualquier tipo de obligatoriedad en lo que a decisiones anteriores los tribunales hayan resuelto sobre debates con los mismos fundamentos jurídicos, pese a que como en el caso del Consejo de Estado Francés, el desarrollo jurisprudencial haya tenido especial importancia.

Si bien Colombia posee una clara influencia del Derecho continental europeo, desde tiempo atrás se viene presentando un debate nacional en torno al sistema de fuentes del Derecho con miras a categorizar la jurisprudencia como su fuente formal principal y no de acuerdo con la concepción tradicional que la consideraba un mero criterio auxiliar. Para la definición del desarrollo conceptual en nuestro medio debemos distinguir varios períodos que enmarcan visiones diferentes en cuanto a la jurisprudencia como fuente del Derecho, y a la obligatoriedad, que el precedente jurisprudencial comporta frente a las decisiones judiciales y de las autoridades administrativas.

La influencia del Derecho continental europeo trajo consigo un primer período enmarcado dentro del debate o contraposición de los criterios de "doctrina legal" claramente de origen español enmarcado por el artículo 10 de la Ley 153 de 1887, que reza: “... en casos dudosos, los Jueces aplicarán la doctrina legal más probable. Tres decisiones uniformes dadas por la Corte Suprema, como Tribunal de Casación, sobre un mismo punto de Derecho, constituyen doctrina legal probable" y el artículo 371 de la Ley 105 de 1890, referida a:

"Es doctrina legal la interpretación que la Corte Suprema dé a unas mismas leyes en dos decisiones uniformes. También constituyen doctrina legal las declaraciones que la misma Corte haga en dos decisiones uniformes para llenar los vacíos que ocurran, es decir, en fuerza de la necesidad de que una cuestión dada no quede sin resolver por no existir ley apropiada al caso".

Adicionalmente, el artículo 369 de esta última prevé como causal de casación la violación a la doctrina legal. Es decir, que era 
obligación del juez en todos los casos tomar una decisión frente al debate que se proponía y al tiempo que debía tener en cuenta un número de decisiones uniformes adoptadas por la Corte Suprema de Justicia como sustento para esta. Ello en contraposición del contenido del artículo 7 del Código Civil que establece:

"Las sentencias judiciales no tienen fuerza obligatoria sino respecto de las causas en que fueron pronunciadas. Es, por tanto, prohibido a los jueces proveer en los negocios de su competencia por vía de disposición general o reglamentaria", que corresponde a la disposición de darle únicamente valor inter-partes a la jurisprudencia.

Este período se prolongó hasta la expedición de la Ley 169 de 1896 en su artículo 4 que para el efecto reza:

"Tres decisiones uniformes, dadas por la Corte Suprema como Tribunal de Casación, sobre un mismo punto de derecho, constituyen doctrina probable, y los jueces podrán aplicarla en casos análogos, lo cual no obsta para que la Corte varíe la doctrina en caso de que juzgue erróneas las decisiones anteriores".

La aparición de la Ley 169 de 1896, y más específicamente de su artículo 4, puede considerarse como el punto de partida del segundo período de desarrollo del tema jurisprudencial de precedente o sus anteceden- tes, ya que esta normativa, aún vigente, ha sido empleada como soporte para definir el alcance que el concepto de precedente jurisprudencial tiene en la actualidad, en cuanto a las jurisdicciones ordinaria y contenciosoadministrativa, debido a que la Corte Constitucional en la revisión de la norma le dio un sentido trascendente, a partir de la ampliación del alcance de la noción de "doctrina probable" allí previsto.

Sin embargo, hasta antes de la redefinición del alcance normativo, que el concepto de "doctrina probable" comporta, podríamos establecer que si bien estos criterios sirvieron de referente frente a la toma de muchas decisiones jurisdiccionales, en la práctica carecían de la obligatoriedad que este tipo de materias exige, dada la necesidad de generar seguridad jurídica a los ciudadanos, mutua confianza y garantizar el principio a la igualdad, cuando en la aplicación de la ley, para casos con fundamentos similares, se exige que el juez adopte sus decisiones en un mismo sentido. En resumen, durante el período de aplicación de este criterio las reglas generadas no tenían un carácter vinculante concreto y por ello no era dable hacer exigible ante los jueces su aplicación.

\subsection{El giro en la mirada: el papel de la Corte Constitucional}

Luego de la promulgación de la Constitución de 1991, la cual trajo consigo la noción según la cual la Constitución es Norma de Normas, surge un activismo evidente ya que adquiere fuerza vinculante desde el preámbulo mismo, pasando por la definición del concepto 
de derechos fundamentales y materializando los derechos ciudadanos a participar en la toma de las decisiones del Estado.

Ello, desde luego se estructuró sobre la base de la creación de la Corte Constitucional, la cual tiene bajo su égida garantizar la integridad de la aplicación de los principios, reglas y derechos contemplados en la Constitución. Pero uno de los debates de mayor connotación ha sido el generado por el contraste entre el artículo 230 de la C.P. que a la sazón establece:

"Los jueces, en sus providencias, solo están sometidos al imperio de la ley. La equidad, la jurisprudencia, los principios generales del Derecho y la doctrina son criterios auxiliares de la actividad judicial", frente al alcance del artículo 241 que a su vez establece: "A la Corte Constitucional se le confía la guarda de la integridad y supremacía de la Constitución...".

Para quienes realizan una interpretación exegética el artículo 230 agota cualquier tipo de interpretación, por lo cual la ley es la única fuente formal principal del Derecho. Pero para otros, que realizan un análisis sistémico, el mismo artículo está referido a que la noción de ley hace alusión al concepto de norma jurídica en general, es decir, Constitución, ley, actos administrativos, etc., y que siendo la jurisprudencia parte de este, debe mirarse integral y armónicamente, de esa forma, y por consiguiente, enmarcado dentro de la misma definición.
Así las cosas, la materialización de la función de guardiana de la Constitución tiene indefectiblemente que hacerse definiendo una armazón que le permita al conglomerado conocer el alcance interpretativo frente a los diferentes derechos fundamentales, lo cual entendemos suficientemente claro. Es así que la Corte Constitucional, de forma contundente, ha adoptado una posición categórica en cuanto a que el precedente judicial es obligatorio, considerando la ratio decidendi o el fundamento en que se soportan los fallos de tutela y contenciosos, deben servir de soporte para los fallos posteriores.

También es clara la posición de la Corte Constitucional en el sentido de establecer criterios para que los jueces, sin desconocer su independencia, deban garantizar la seguridad jurídica, la confianza mutua y el principio a la igualdad. Ello a partir de la exigencia relativa a que si bien pueden apartarse del precedente, lo puedan hacer, siempre y cuando evalúen el contenido del existente y se expongan las razones por las cuales adoptan una decisión en sentido diferente.

Pero más allá de esta aparente simple interpretación, se encuentra el auge del debate sobre la necesidad de que el precedente se aplique ya no solo para la jurisdicción constitucional, frente a las materias que le son propias, sino con relación a las demás jurisdicciones; es decir, la ordinaria y la contencioso administrativa. De manera que, se está asistiendo a una exigencia por vía jurisprudencial que viene arrastrando la creación legal, para que se garantice, en el marco de un Estado 
Social de Derecho, el principio de igualdad ciudadana, mutua confianza y de seguridad jurídica, por vía de la implementación del criterio del precedente jurisprudencial.

Parecería entonces que no son voces aisladas las que demandan y consolidan el avance en esta materia y lejos de corresponder a un mero capricho por traer mecanismos de otras latitudes, en la práctica, con la carga argumentativa, se pretende construir la necesidad de consolidar el precedente jurisprudencial como fuente formal principal del Derecho en nuestro país.

Es así que la Corte Constitucional en su afán de concretar las reglas que permitan ordenar el sistema jurídico que surge del cuerpo constitucional, no solo ha tratado de avanzar en la implementación del sistema de precedente jurisprudencial desde el ámbito constitucional, esto es, estableciendo reglas o mecanismos que permitan ordenar el empleo de dicha fuente, sino que al tiempo ha venido madurando la implementación del mismo criterio frente a la jurisprudencia de la Corte Suprema de Justicia y del Consejo de Estado.

En ese sentido, ha exigido implícitamente, que estos entren en un proceso de adecuación organizacional y metodológica, de manera que el precedente jurisprudencial pueda ser implementado a cabalidad, ya no sustentado en las disposiciones legales, sino directamente de la ordenación y sistematización de la jurisprudencia misma. Parafraseando a Diego López (2007), el aumento del valor de la jurisprudencia comienza a darse a partir de la Constitución de 1991 con el surgimiento de la Corte Constitucional, cuya corporación inicia su proceso de desarrollo funcional y conceptual tratando de consolidar el régimen de precedente constitucional de forma vacilante.

Sin embargo, se podría decir que durante este período surge el criterio de "Doctrina Constitucional", con rasgos diferenciales entre las decisiones de la Corte Constitucional durante el período de 1991 a 1995, con la expedición también del Decreto 2067/91, sobre los mecanismos constitucionales, como la tutela, en cuyo lapso dicha Corporación osciló en la definición de la jurisprudencia de tutela dándole el carácter de valor pedagógico, normativo general y auxiliaridad de los fallos con efectos inter-partes, de aquellas expedidas durante el período de 1995 a 1998, en el que se presenta un avance conceptual que parte de la restricción del alcance del Decreto 2067/91, sobre la cual "la Corte reconstruye una doctrina fuerte de precedentes, primero, mediante la utilización expansiva del concepto de "doctrina constitucional" $y$, segundo, mediante la utilización del principio de igualdad" (Constitución Política de 1991, p. 13).

Esta línea argumentativa terminará triunfando al interior de la Corte, que finalmente anuncia de manera unánime y en sala plena una doctrina fuerte del precedente en la Sentencia C-037/96 con la que desarticula el sentido tradicionalista del artículo 48 de la Ley 270 de 1996 . Esta contenía un ataque 
frontal contra la capacidad interpretativa de la Corte en todos aquellos aspectos que habían generado polémica pública hasta ese momento, en especial, las técnicas de modulación de sentencias y, por supuesto, la doctrina de precedentes. En la Sentencia C-037 la Corte defiende sus facultades en relación con ambos aspectos. Es seguro decir que luego de esta sentencia todos los magistrados de esta 2a Corte empiezan a apoyar la tesis de la obligatoriedad del precedente. Tal línea jurisprudencial es confirmada ulteriormente en la Sentencia SU-047/99 y, en general, en la práctica decisional de la Corte (López Medina, 2007, p. 104).

En el mismo período coexistieron los criterios antes mencionados con el de la "Doctrina Probable" a que ya hicimos referencia, que como se manifestó carecía de obligatoriedad y tenían un "valor meramente persuasivo" (López Medina, 2007, p. 105), el que a su vez vino a prolongarse hasta la reinterpretación que del mismo hizo la Corte Constitucional mediante Sentencia C-836 de 2001.

3. ¿Fortalecimiento de la fuerza vinculante del precedente judicial en el marco de la Ley 1437 de 2011?

\subsection{La fuerza vinculante del precedente}

Enmarcándonos en el análisis anterior y siguiendo la reflexión inicial, es bueno señalar que en la Sentencia C-439 de 2000, la Corte Constitucional precisa que como resultado de los cambios estructurales a nivel institucional propuestos por la Constitución de 1991, con relación al precedente judicial lo siguiente:
"Los jueces están obligados a acatar los precedentes que fijen sus superiores. En los casos contenciosos, la ratio decidendi guarda relación directa con los hechos sometidos a consideración del juez pues, a partir de la situación fáctica tenida en cuenta por el juez, este precisa el sentido de la norma jurídica, configurándose una norma (regla), de origen judicial, derivada de la disposición positiva. Las posibilidades de creación de estas normas, cabe señalar, no es infinita, pues el ámbito de decisión judicial se encuentra limitado por el texto de la norma positiva. Las técnicas y métodos de interpretación, que no se limitan a los establecidos en el Código Civil y en la Ley 153 de 1887, imponen cánones interpretativos, que permiten determinar si el sentido que se atribuye a la norma, realmente es correcto. Así las cosas, la ratio decidendi, además de ser el fundamento normativo de la decisión judicial, define, frente a una situación fáctica determinada, la correcta interpretación $-y$, por ende, la correcta aplicaciónde una norma. Esta definición de la correcta interpretación y aplicación de una norma, frente a un caso concreto, tiene por efecto que todo funcionario, no solo judicial, está en la obligación de aplicar e interpretar las normas, en el sentido dictado por el juez, de igual manera, en todo evento en el cual la situación fáctica concuerde, en lo esencial, con los hechos considerados al construirse la ratio decidendi" (Cor- 
te Constitucional. Sentencia C-439 de 2000. Magistrado ponente: Alejandro Martínez Caballero. Bogotá, D.C., abril 14 de 2000).

No obstante, a pesar de lo dispuesto por la Corte no se pueden ocultar las situaciones conflictivas que se viven en el ejercicio mismo del accionar de los operadores de la Administración de Justicia, que sin duda alguna evidencia una situación conflictiva latente, como es el caso de:

“... la ancestral discusión entre quienes, apegados a la tradición, luchan por la primacía de la ley y su aplicación escueta por parte del juez -la boca que pronuncia palabras del legislador- y quienes aspiran a fortalecer la labor judicial predicando la fuerza vinculante -para todos los operadores jurídicos- de los fallos proferidos por las Altas Cortes" (Corte Constitucional. Sentencia C-252 de 2001).

Por ende, es válido señalar la situación ocurrida con la expedición de la Ley 270 de 1996, estatutaria de la Administración de Justicia, el Congreso de la República, precisó que "solo la interpretación que por vía de autoridad hace el Congreso de la República tiene el carácter obligatorio general", y la Corte de forma expresa reconoció con la Sentencia C-037 de 1996, la inconstitucionalidad de las expresiones "solo" y "el Congreso de la República", dejando en firme que:

"La labor de la Corte Constitucional encaminada a guardar la supremacía y la integridad de la Corte, hace que ella sea la responsable de interpretar con autoridad y de definir los alcances de los preceptos contenidos en la ley fundamental" (Corte Constitucional. Sentencia T-037 de 1996. Magistrado ponente: Vladimiro Naranjo Mesa. Bogotá, agosto 12 de 1996).

Como lo precisa la misma Corte, lo anterior implica que en Colombia los jueces tienen la obligación de atender los instrumentos legítimos a través de los cuales se manifiesta el Derecho y uno de estos, es ahora la jurisprudencia, que se viene a sumar a los ya tradicionales -Constitución y ley-, con lo cual se expresa, por lógica, una fuerte teoría de Precedente Judicial.

Es por ello que se hace importante referenciar el numeral segundo del artículo 48 de la misma Ley 270 de 1996, que para el efecto dispone: "... las decisiones judiciales adoptadas en ejercicio de la acción de tutela tienen carácter obligatorio únicamente para las partes, y que, por otra parte, su motivación solo constituye criterio auxiliar para la actividad de los jueces...".

Al respecto la Corte declaró la exequibilidad condicionada a una explicación del proceder decisional, es decir, si los jueces optan por separarse de la línea jurisprudencial trazada en estas decisiones, se verán compelidos a justificar de manera suficiente y adecuada las motivaciones que les llevan a hacerlo, de lo contrario se verían constriñendo el principio de igualdad. 
Sobre la base de las ideas expuestas, jurídicamente, se puede hablar del precedente legislativo o administrativo para hacer referencia a lo que antecedió a una ley o a una actuación gubernativa, la importancia del concepto se destaca en lo judicial y, fundamentalmente, en lo judicial constitucional, tal y como lo establece nuevamente la Corte Constitucional.

"Se trata de establecer que los Tribunales, y en especial el constitucional por la índole macro que representa, deben ser consistentes o consecuentes con las decisiones que toman como una forma de expresión del respeto a un Estado de Derecho, porque es obvio que los jueces no pueden tomar sus decisiones de fondo con base en simples caprichos o criterios ligeros, sino con fundamento en reglas jurídicas o principios que no solo han sido ya aplicados a otros casos sino que ellos mismos y los demás estarían dispuestos a aplicar en casos semejantes en el futuro..." (Corte Constitucional. Sentencia T-579 de 2001).

La misma Corte expone que toda esta conceptualización o presupuestos y criterios jurídicos, se pueden sintetizar de forma clara y sencilla en la Sentencia C-447 de 1997, en la que de forma precisa, coherente, lógica, y contundente se afirma:

"Todo Tribunal y en especial la Corte Constitucional, tiene la obligación de ser consistente con sus decisiones pre- vias. Ello deriva no solo de elementales consideraciones de seguridad jurídica - pues las decisiones de los jueces deben ser razonablemente previsibles- sino también del respeto al principio de igualdad, puesto que no es justo que casos iguales sean resueltos de manera distinta por un mismo juez. Por eso, algunos sectores de la doctrina consideran que el respeto al precedente es al Derecho lo que el principio de universalización y el categórico son a la ética, puesto que es buen juez aquel que dicta una decisión que estaría dispuesto a suscribir en otro supuesto diferente que presente caracteres análogos, y que efectivamente lo hace. Por ello, la Corte debe ser muy consistente y cuidadosa en el respeto de los criterios jurisprudenciales que han servido de base ratio decidendi de sus precedentes decisiones" (Corte Constitucional. Sentencia C-447 de 1997).

Visto así, en los términos de la Corte, los precedentes desempeñan funciones básicas en los ordenamientos jurídicos, aún en aquellos de carácter legislado como el colombiano, debido a esto, el Tribunal y en especial el juez constitucional, deben ser enteramente conscientes de las decisiones tomadas con anterioridad. Es decir, que enmarcado en conceptualizaciones previas, se crea un vínculo derivado de la responsabilidad que debe asistir a los jueces, frente a una decisión anterior, la cual fue fruto de una valoración y obviamente de un análisis jurídico que no se puede despreciar. 
En la doctrina nacional se han presentado algunas objeciones de prudencia sobre el tema del Precedente Judicial aun en quienes son sus defensores, estos estiman que con el paso del tiempo, el precedente puede estancarse, cristalizarse y perder el sentido garantista y de cambio que tiene en su esencia, especialmente si su sustento se encuentra basado en rígidos tecnicismos de interpretación que alejarían al sujeto de ciudadanía la comprensión sencilla del texto y el alcance de la Norma Constitucional.

En cuanto al tema que se está estudiando en este aparte, la Jurisdicción Contencioso Administrativa se constituye en la garantía del cumplimiento del Principio de la Legalidad, aplicado a la Administración Pública en sus tres niveles político-territoriales: nacional, estatal y municipal. Ello es el producto del Estado Social de Derecho, en el cual se encuentra la posibilidad abierta, constitucionalmente, a la ciudadanía de poder encauzar los actos, hechos y actuaciones de la Administración Pública a su control y vigilancia por parte de los órganos judiciales especializados que la conforman.

Es por ello que, el nuevo Código Contencioso Administrativo busca reformar la jurisdicción contencioso administrativa, en cuanto a la reducción de los procedimientos internos de la administración, los procedimientos judiciales que se aplican en la jurisdicción y la creación de una sola acción con múltiples pretensiones, respecto al Decreto 1 de 1984. De otra parte, se orienta a proteger las acciones de los gobernantes de una forma más objetiva, a través de la dinamización de los servicios que ofrece la Administración, en pro de la internacionalización y modernización del aparato administrativo y de sus tensiones conflictivas; ofreciéndole al ciudadano la posibilidad de exigir judicialmente sus derechos fundamentales consagrados en la Constitución Nacional, antes de que se pronuncie la Administración. En este sentido el artículo 10 de la Ley 1437 de 2011 establece:

"Artículo 10. Deber de aplicación uniforme de las normas y la jurisprudencia. Al resolver los asuntos de su competencia, las autoridades aplicarán las disposiciones constitucionales, legales y reglamentarias de manera uniforme a situaciones que tengan los mismos supuestos fácticos y jurídicos. Con este propósito, al adoptar las decisiones de su competencia, deberán tener en cuenta las sentencias de unificación jurisprudencial del Consejo de Estado en las que se interpreten y apliquen dichas normas".

Se destaca del artículo anterior, el hecho de que las autoridades administrativas tendrán en cuenta, ad latere de las sentencias de unificación jurisprudencial proferidas por el Consejo de Estado y de manera preferencial, las decisiones de la Corte Constitucional que aclaren las normas constitucionales conducentes a las soluciones de los asuntos de su competencia. Esto, sin perjuicio del carácter obligatorio erga omnes de las sentencias que efectúan el control abstracto de constitucionalidad. 
Con referencia a esto, se encuentra, que el artículo 10 de la Ley 1437 de 2011 regula el deber de aplicación uniforme de las normas y la jurisprudencia. En este sentido, señala que las autoridades administrativas al resolver los asuntos de su competencia, aplicarán las disposiciones constitucionales, legales y reglamentarias de manera uniforme a situaciones que tengan los mismos supuestos fácticos y jurídicos. De ahí que, se establezca que el artículo es extensivo de la Norma Constitucional que enmarca el tema en estudio: la legalidad e igualdad ante la ley, que implica la obligación de fundar las actuaciones del Estado en las fuentes de derecho preexistentes y bajo el mandato de concebir idéntico tratamiento ante supuestos jurídicos y fácticos análogos.

Integra además el artículo 10 el "tener en cuenta", que no es otra cosa que la obligación de las autoridades en hacer uso o referenciar las sentencias de unificación jurisprudencial que adopte el Consejo de Estado en las que se interpreten dichas normas:

"La Corte observa que este precepto reconoce una fuente de derecho particular, que debe hacer parte del análisis para la adopción de decisiones, a la cual el legislador le reconoce carácter vinculante mas no obligatorio, pues la disposición alude a que el precedente debe ser consultado, pero no aplicado coactivamente" (Corte Constitucional. Sentencia C-634 de 2011).

Indica que las autoridades a las que hace mención, son aquellas que cumplen una función administrativa, con exclusión de la competencia jurisdiccional, de conformidad con lo previsto en el artículo 20 de la Ley 1437 de 2011 y habida cuenta que el artículo 10 está ubicado en la primera parte del Código, cuya finalidad es:

“... proteger y garantizar los derechos y libertades de las personas, la primacía de los intereses generales, la sujeción de las autoridades a la Constitución y demás preceptos del ordenamiento jurídico, el cumplimiento de los fines estatales, el funcionamiento eficiente y democrático de la administración y la observancia de los deberes del Estado y de los particulares" (Corte Constitucional. Sentencia C-634 de 2011).

Implica lo anterior, que la norma tiene un carácter de deber general de la administración pública, que sirve de principio rector para su funcionamiento, de manera que se vincula a las autoridades administrativas a las decisiones de unificación de jurisprudencia del Consejo de Estado, con el fin de evitar que las personas deban acudir a la jurisdicción para obtener el reconocimiento de derechos que en sede judicial ya han sido aceptados. Con tal propósito, se impone un deber general de observancia de las decisiones de unificación, por parte de las autoridades administrativas, en el ejercicio de sus competencias. Para estas autoridades no es aplicable el principio de autonomía o independencia válido para los jueces, según lo dispuesto en el artículo 230 de la Constitución Política. 
3.2. La fundamentación constitucional del precedente para los funcionarios públicos: preguntas pendientes

La Corte reitera el sometimiento de las autoridades administrativas al imperio de la Constitución y la ley, entendido como la aplicación del conjunto de normas constitucionales y legales, incluyendo la interpretación jurisprudencial de los máximos órganos judiciales. Al respecto en Sentencia C-539 de 2011 se establece, en relación al precedente judicial, por parte de las autoridades administrativas la siguiente fundamentación (Corte Constitucional. Sentencia C-539 de 2011):

- En el respeto del debido proceso y del principio de legalidad en materia administrativa (arts. 29, 121 y 122 C.P.);

- En que el contenido y alcance normativo de la Constitución y la ley es fijado válida y legítimamente por las Altas Cortes, cuyas decisiones hacen tránsito a cosa juzgada y tienen fuerza vinculante;

- En que las decisiones de las autoridades administrativas no pueden ser arbitrarias y deben fundamentarse de manera objetiva y razonable;

- En que el desconocimiento del precedente y con ello del principio de legalidad implica la responsabilidad de los servidores públicos (arts. 6 y 90 C.P.) y

- En que las actuaciones y decisiones de las autoridades administrativas deben respetar la igualdad de todos ante la ley (art. 13 C.P.).

Sin embargo, esta innovación estipulada en el nuevo Código Contencioso Administrativo, el de la fuerza vinculante que debe tener el
Precedente Judicial, podría presentar serios problemas en su curso, pues nada asegura que tenga un desarrollo totalmente armónico en la función pública, con pleno acatamiento de sus servidores a esta nueva propuesta de entender el funcionamiento de lo jurídico.

De hecho, esa problemática aumenta, en la práctica, al no existir claridad sobre la fuerza vinculante de estos propósitos para quienes pertenecen a la administración pública y tengan bajo su decisión aspectos de trascendencia; y la duda que surge es cuáles serán las autoridades que controlarán a estos funcionarios públicos que no tengan en cuenta los precedentes judiciales. Surgen allí varios interrogantes que necesariamente obligan a pensar:

- ¿Qué tipo de sanciones disciplinarias se crearían para los servidores que no acaten la fuerza vinculante de los precedentes judiciales?

- ¿Cómo se obligará a todos los servidores que toman decisiones en el sector público a estudiar a fondo las disímiles y múltiples decisiones judiciales que se presentan en los altos Tribunales y en las Altas Cortes, para así no tomar decisiones erradas al momento de aplicar o no el precedente?

- ¿Será capaz un funcionario público, sin la profesión de abogado y sin ningún tipo de formación jurídica, obedecer la pretensión del precedente judicial y todas las consecuencias derivadas de ellos?

- ¿Qué rol puede cumplir el ciudadano? ¿Deberá concurrir a alguna autoridad 
para preventivamente asegurarse de la expedición de un acto administrativo conforme a Derecho y conforme a determinados precedentes judiciales?

- ¿En caso de que un ciudadano reciba como respuesta, un acto administrativo contrario a la ley y a la jurisprudencia reiterada previamente, se darán sanciones ejemplarizantes para esos funcionarios?

- ¿Podrá por medio de la interposición de un recurso, el ciudadano de a pie, tener respuestas afirmativas de la administración, al asistir a alguna institución pública que constriña al funcionario a someterse a los mencionados precedentes?

Estas preguntas aún no tienen una respuesta en el marco de una normatividad y se hace vital e imperativo responderlas, para que exista un principio unificador en el funcionamiento del nuevo código, de manera que se enlace a las autoridades administrativas a las decisiones de unificación de jurisprudencia del Consejo de Estado, de la Corte Suprema o de la Corte Constitucional, con el fin de impedir que ante la identidad de presupuestos jurídicos, las personas deban acudir a la jurisdicción para obtener el reconocimiento de sus derechos que ya han sido reconocidos.

En tal sentido, es imperioso que la Procuraduría General de la Nación se disponga a iniciar investigaciones disciplinarias, en aquellos casos de funcionarios que sean renuentes a atender casos que le corresponda estudiar, en asuntos ya resueltos por las Altas Cortes, esto es tesis y posturas que en otros escenarios judiciales ya han sido aceptados, los cuales se deben resolver en similar sentido.
Así mismo, debe existir la posibilidad que el Consejo de Estado (alguna sala especial o la misma sala de consulta y servicio civil), la Corte Constitucional, el Consejo Superior de la Judicatura o una nueva Corte, asuma la competencia en este campo y que se tenga la posibilidad de dilucidar aspectos de importancia para los ciudadanos o para las mismas entidades estatales, en aquellos casos en donde no se tenga claridad si ya existe precedente judicial y si se puede aplicar en la administración pública. Es decir, iniciar la tarea postergada de unificar los precedentes judiciales por áreas y temáticas o por líneas jurisprudenciales.

Todo esto generaría una mayor certeza jurídica y brindaría la posibilidad de no estar sujeta esta norma a la discrecionalidad y a la impunidad para funcionarios renuentes. A su vez, tendrá el Estado la responsabilidad de capacitar en forma permanente a los servidores públicos y, de alguna manera, absolver rápidamente las dudas que se presentarán en las entidades del Estado en sus distintos niveles. Igualmente los ciudadanos necesitan gozar de un Estado garantista en este aspecto, que rápidamente les asesore o intervenga cuando esté latente una petición o la solicitud de un derecho y alguna entidad se rehúse a consagrarlo o a cumplir su deber público. De igual manera, constituye un aporte para el funcionamiento del Estado, el hecho de que la reforma esté pensada bajo la necesidad de hacer que los procedimientos sean más simples, rápidos y eficientes en la relación ciudadanía-Estado. 
Por lo tanto, como se expresó en párrafos anteriores, la última palabra la tiene el Consejo de Estado y la Corte Suprema de Justicia por ser las llamadas a ajustar sus organizaciones internas a los retos que el inminente fluctuar del precedente trae consigo, como garantía de seguridad jurídica para los ciudadanos. Pero, en el contexto actual, cuando existan precedentes claros en algunas materias y las autoridades administrativas evadan su aplicación, podría la ciudadanía acudir ante los organismos de control, para que a través de las funciones de advertencia o sancionatorias se evite que la conducta renuente de los servidores públicos determine el desconocimiento de derechos particulares y posibles detrimentos para el patrimonio de las entidades estatales.

\section{CONCLUSIONES}

El estudio bibliográfico y de análisis comparado permite colegir que las autoridades administrativas deben tener en cuenta, en la adopción de sus decisiones, no solo las reglas de derecho expresadas por las sentencias de unificación que adopte el Consejo de Estado, lo cual resulta plenamente compatible con la Constitución, sino también a la jurisprudencia proferida por la Corte Constitucional en ejercicio del control de constitucionalidad abstracto y concreto, merced a la vigencia del principio de supremacía constitucional (art. 4으. C.) y los efectos de la cosa juzgada constitucional regulados en el artículo 243 de la Carta Política.

Propender por el entendimiento contrario de esta lógica jurídica, significaría desconocer el artículo 241 superior, mandato que confía a la Corte Constitucional la salvaguarda de la integridad y supremacía de la Constitución. El artículo 10 del nuevo Código de Procedimiento Administrativo, deja claro que el funcionario administrativo no debe desconocer los pronunciamientos de las Altas Cortes y el carácter vinculante de la jurisprudencia. El no tener en cuenta el referente constitucional de conformidad con los pronunciamientos del Consejo de Estado, implica desconocer el papel que cumplen estos órganos.

La situación descrita anteriormente, impone el deber general de observancia de las decisiones de unificación por parte de las autoridades administrativas, en el ejercicio de sus competencias. Para estas autoridades no es aplicable el principio de autonomía o independencia válido para los jueces, según lo dispuesto el artículo 230 de la Constitución Política. La Corte ha reiterado el sometimiento de las autoridades administrativas al imperio de la Constitución y la ley, entendido como la puesta en práctica del conjunto de normas constitucionales y legales, incluyendo la interpretación jurisprudencial de los máximos órganos judiciales. Así mismo, queda altamente desarrollada la idea de que debe existir un marco legal que obligue a los funcionarios a cumplir este cometido, so pena de ser sancionados disciplinariamente.

Como se puede inferir, es previsible y necesaria la creación de un ente o la asignación de funciones a alguno ya existente (Corte Constitucional, Consejo de Estado, Consejo 
Superior de la Judicatura), para que sean el soporte de los ciudadanos y de las entidades estatales, en caso de dudas frente a la aplicación de los precedentes judiciales; debe ser un órgano de consulta, pero a su vez vinculante, que absuelva las dudas y consultas, cuando no exista certeza por parte de los funcionarios públicos o que resuelva quejas planteadas por cualquier particular.

\section{REFERENCIAS BIBLIOGRÁFICAS}

Ahumada Ruiz, M. Á. (2003). Stare decisis y creación judicial de Derecho Constitucional. A propósito del precedente constitucional en el sistema judicial norteamericano, de Ana Laura Magaloni Kerpel. Revista Española de Derecho Constitucional, 23(67).

Bernal Pulido, C. (2008). El precedente en CoIombia. En: Revista Derecho del Estado, (21), 81-94, diciembre. http://foros.uexternado. edu.co/ecoinstitucional/index.php. [Rev. dic 10 de 2011]

Botero Bernal, A. (2003). Diagnóstico de la eficacia del Derecho y otros ensayos. MedeIlín: Señal Editora.

Buitrago Guzmán, M. R. (2011). Metodología del precedente judicial en la Corte Constitucional y la Sala Laboral de la Corte Suprema de Justicia, en materia de Derecho del Trabajo y de la seguridad social. Tesis de Maestría. Bogotá: Universidad Nacional de Colombia.

Cajas Sarria, M. A. (2009). Minimalismo judicial: ¿Cass sunstein en la Corte Constitucio- nal? En: Revista Mexicana de Derecho Constitucional, (20), 1-61. Enero-junio. [En línea]: http://biblio.juridicas.unam.mx/revista/pdf/ CuestionesConstitucionales/20/ard/ard1. pdf. [Rev. dic 10 de 2011].

Corte Suprema de Justicia de la Nación. FaIlo 1985/07/04. Cerámica San Lorenzo, S. A. Buenos Aires, julio 4 de 1985.

Corte Constitucional. Sentencia C-252 de 2001. M. P. Carlos Gaviria Díaz. Bogotá, D.C., febrero 28 de 2001.

Corte Constitucional. Sentencia C-539 de 2011. M. P. Luis Ernesto Vargas Silva. Bogotá, D.C., julio 6 de 2011.

Corte Constitucional. Sentencia C-634 de 2011. M. P. Luis Ernesto Vargas Silva. Bogotá, D.C., agosto 24 de 2011.

Corte Constitucional. Sentencia C-037 de 1996. M. P. Vladimiro Naranjo Mesa. Bogotá, agosto 12 de 1996.

Corte Constitucional. Sentencia T-321 de 1998. M. P. Alfredo Beltrán Sierra. Bogotá, D.C., julio 2 de 1998.

Corte Constitucional. Sentencia T-337 de 1995. M. P. Eduardo Cifuentes Muñoz. Bogotá, D.C., julio 26 de 1995.

Corte Constitucional. Sentencia C-439 de 2000. M. P. Alejandro Martínez Caballero. Bogotá, D.C., abril 14 de 2000. 
Corte Constitucional. Sentencia C-447 de 1997. M. P. Alejandro Martínez Caballero. Bogotá, D.C., febrero 17 de 1997.

Corte Constitucional. Sentencia T-569 de 2001. M. P. Eduardo Montealegre Lynett. Bogotá, D.C., junio 5 de 2001.

Corte Constitucional. Sentencia T-566 de 1998. M. P. Eduardo Cifuentes Muñoz. Bogotá, D.C., octubre 7 de 1998.

Corte Constitucional. Sentencia C-816 de 2011. M. P. Mauricio González Cuervo. Bogotá, D.C., noviembre de 2011.

Corte Constitucional. Sentencia SU-047 de 1999. M. P. Carlos Gaviria Díaz. Bogotá, D.C., enero 29 de 1999.

Corte Constitucional. Sentencia T-1625 de 2000. M. P. Martha Victoria Sáchica Méndez. Bogotá, D.C., noviembre 23 de 2000.

Corte Constitucional. Sentencia C-836 de 2001. M. P. Rodrigo Escobar Gil. Bogotá, D.C., agosto 9 de 2001.

Corte Constitucional. Sentencia SU-1300 de 2001. M. P. Vladimiro Naranjo Mesa. Bogotá, D.C., diciembre 6 de 2001.

Corte Constitucional. Sentencia T-057 de 2006. M. P. Álvaro Tafur Galvis. Bogotá, D.C., febrero 2 de 2006.

Corte Constitucional. Sentencia T-116 de 2004. M. P. Eduardo Montealegre Lynett. Bogota, D.C., febrero 12 de 2004.
Echavarría, H. (2010). Reforma al Código Contencioso Administrativo. En: Observatorio Legislativo. Boletín No. 156, marzo. Colombia: Instituto de Ciencia Política.

García Martínez, F. y Torres Zárate, F. (2008). Common law: una reflexión comparativa entre el sistema inglés y el sistema estadounidense. Alegatos, (68-69). México: Universidad Autónoma de México.

Gómez Higuera, L. P. y Robles Martínez, F. E. (2011). La jurisprudencia constitucional como fuente del Derecho. Enfoque desde el operador judicial. En: La crisis de las fuentes del Derecho en la globalización. Medellín: Dike.

González Martín, N. (2011). Common law: Especial referencia a los Restatemen of the Law en Estados Unidos. Instituto de Investigaciones Jurídicas de la Universidad Autónoma de México. [http://biblio.juridicas.unam. $\mathrm{mx} /$ libros/4/1968/19.pdf]

Hernández, R., Fernández, C. y Baptista, P. (2010). Metodología de la investigación. México: McGraw-Hill.

Iturralde, V. (1995). El precedente en el Common law. Madrid: Editorial Civitas.

Legarre, S., Rivera, J. C. (2011). Naturaleza y dimensiones del stare decisis. En: Revista Chilena de Derecho, 33(1). Abril de 2006, 109-124. [En línea]: http://www.scielo.cl /scielo.php?pid=S0718-343720060 00100007\&script=sci_arttext. [Rev. dic 10 de 2011]. 
Londoño, N. R. (2007). La obligatoriedad de los principios del Derecho en el Common law de los Estados Unidos. Revista Facultad de Derecho y Ciencias Políticas, 3(106). Medellín.

López Medina, D. E. (2002). Interpretación constitucional. Bogotá: Consejo Nacional de la Judicatura.

López Medina, D. E. (2007). El derecho de los jueces. Bogotá: Legis-Uniandes.

Mirneau, M. (2004). Una Introducción al Common law. Instituto de Investigaciones Jurídicas. Serie Estudios Jurídicos, (4). México: Universidad Nacional Autónoma de México.

Montoya Medina, L. E. (2011). La excepción hace la regla: el Derecho Judicial. El precedente judicial en el discurso de las fuentes del Derecho. Bogotá: Editorial Ibáñez.

Olano García, H. A. (2009). Consulta. ¿Qué se entiende por reiterada jurisprudencia?, es decir, ¿cuántos pronunciamientos debe tener un asunto? En: Academia Colombiana de Jurisprudencia. Bogotá, marzo 27 de 2009. [En línea]: http://www.acj.org.co/conceptos/concep_ord_003-2009.htm [Rev. dic 10 de 2011].

Pilonieta Pinilla, E. (2007). Obligatoriedad del precedente jurisprudencial en el sistema jurídico colombiano. Trabajo de posesión como Miembro Correspondiente de la Academia Colombiana de Jurisprudencia. Bucaramanga.
Sánchez Gil, R. (2009). El derecho de los jueces. Revista Boletín Mexicano del Derecho Comparado, XLII(124). Enero-abril. México: Universidad Autónoma de México.

Sangûés, N. P. (2006). La eficacia vinculante de la jurisprudencia de la Corte Suprema de Justicia de EE.UU. y Argentina. Revista del Centro de Estudios Constitucionales, 4(001). Chile: Universidad de Talca.

Tarazona Navas, J. A. (2007). El imperio de la Constitución y del precedente constitucional. Bogotá: Doctrina y Ley.

Tribunal Constitucional del Perú. Sentencia proferida en el Exp. 0024-2003-AI/TC. Lima, Municipalidad Distrital de Lurín. 10 días del mes de octubre de 2005.

Vinatea Medina, R. G. (2010). La aplicación del precedente vinculante del Tribunal Constitucional Peruano en la Jurisprudencia nacional. Pro-justicia. Perú: Centro de Estudios para el Desarrollo de la Justicia. 